\title{
Diet-induced Alterations in Pharmacokinetics of Cefuroxime Axetil in Healthy Chinese Subjects
}

\author{
YING WANG ${ }^{1}$, LIN FAN¹, JUNLIN CHENG, KAIZONG HUANG AND HONGWEI FAN* \\ Department of Clinical Pharmacology Lab, Nanjing First Hospital, Nanjing Medical University, Nanjing 210006, ${ }^{1}$ School of \\ Basic Medicine and Clinical Pharmacy, China Pharmaceutical University, Nanjing 211198, China
}

Wang et al.: Diet-induced Alterations in Pharmacokinetics of Cefuroxime Axetil

\begin{abstract}
This study was conducted to evaluate the pharmacokinetics, safety and gender difference of cefuroxime axetil after single dose administration under fasting and fed conditions in healthy Chinese male and female subjects. In an open-label, two-period study, 26 subjects received a single $250 \mathrm{mg}$ oral dose with or without food. Blood samples were collected at scheduled time points till $24 \mathrm{~h}$ after drug administration and cefuroxime axetil concentration in blood was analysed using liquid chromatography with tandem mass spectrometry. Twenty-three subjects completed the study. Under fed state, the median time to peak plasma concentration of cefuroxime axetil was delayed by approximately $0.5 \mathrm{~h}$ compared with fasting state $(2.23 \mathrm{~h}$ vs. 3.01 h) and there was a $43.9 \%$ increase in the total systemic exposure (AUC0- $\infty$ ) and 8.3, 38.7, 34.1\% reduction in elimination half-life, apparent volume of distribution and apparent clearance, respectively. No significant difference presented in maximum concentration achieved $(p>0.05)$. There was no gender difference in pharmacokinetics and no serious adverse events reported, as well. This study indicated that the extent of absorption of cefuroxime axetil is significantly increased under fed state and it is recommended to be administrated after a meal.
\end{abstract}

Key words: Cefuroxime axetil, food effect, pharmacokinetics, tolerability, gender differences

Cefuroxime axetil (Drugbank CAS number: 64544-07-

$6)$ is an orally available ester prodrug of cefuroxime.
Cefuroxime axetil is a second-generation cephalosporin that has been on the market since $1987^{[1]}$. After oral 
intake, cefuroxime axetil achieved quick absorption in the gastrointestinal system, then hydrolyzed to yield cefuroxime by non-specific esterases in the blood and intestinal mucosa, and the oral bioavailability is greatly improved $^{[2]}$.

For an ester prodrug, the oral bioavailability could be dramatically changed if taken after food ${ }^{[3-5]}$. In terms of oral administration, the bioavailability of the drug only achieved $37 \%{ }^{[6,7]}$ and the absorption of tablet remarkably elevated from 37 to $52 \%$ after a meal ${ }^{[3]}$. The pharmacokinetic characteristics such as peak plasma concentration $\left(\mathrm{T}_{\max }\right)$, peak plasma concentration $\left(\mathrm{C}_{\max }\right)$ and area under curve (AUC) of cefuroxime axetil have been reported and the bioavailability of cefuroxime axetil could be affected by food ${ }^{[3-6,8,9]}$. The effect of food on the pharmacokinetics of cefuroxime axetil was analyzed among Chinese subjects in 1992, in which the pharmacokinetic parameters, particularly apparent clearance (CL) that was obtained from 2 regimens with or without food were compared ${ }^{[10]}$. By way of contrast, pharmacokinetic characteristics and the apparent volume of distribution $(\mathrm{Vd})$ of cefuroxime axetil was compared in current study.

To study the effects of food on their pharmacokinetics, 26 healthy Chinese male and female subjects (19 and 7, respectively) were given $250 \mathrm{mg}$ cefuroxime axetil with or without food. In addition, the safety and tolerability was evaluated, as well as the effect of gender after administration. Twenty-six healthy adult human subjects (7 female subjects) were included. Subjects underwent a screening procedure within $7 \mathrm{~d}$ prior to entering the study. Subjects were eligible to participate if aged $18 \mathrm{y}$ or older with a body mass index (BMI) 19$26 \mathrm{~kg} / \mathrm{m}^{2}$ (inclusive) and male subject's weight should not be less than $50 \mathrm{~kg}$, while weight for female subjects should not be less than $45 \mathrm{~kg}$. Health status was defined by the absence of any active or chronic disease following a detailed medical and surgical history, and a complete physical examination including vital signs, electrocardiogram (ECG) and clinical laboratory tests. All the subjects were non-smokers and took no medication within $2 \mathrm{w}$ prior to the study. Women with childbearing potential were required to have a negative pregnancy test at screening. The study was performed at a phase I clinical research center in strict accordance with the Declaration of Helsinki regarding medical research in humans and was approved by the ethics and research committee of the First Hospital of Nanjing Medical University.

The study was designed as an open-label, two-period study under fasting and fed conditions in healthy, adult male and female subjects. A wash-out period of $14 \mathrm{~d}$ was followed. In the fasting condition, a single oral dose of $250 \mathrm{mg}$ cefuroxime axetil (Zinacef ${ }^{\circledR}$, GSK, C752060) was administered with $240 \mathrm{ml}$ water following an overnight fast of approximately $10 \mathrm{~h}$. In the fed condition, following an overnight fast $(10 \mathrm{~h})$, subjects started the recommended high-fat meal $30 \mathrm{~min}$ before administration. It was required that all subjects finished the meal in $25 \mathrm{~min}$. After taking the high-fat meal, all subjects were administered with a single oral dose of $250 \mathrm{mg}$ cefuroxime axetil and $240 \mathrm{ml}$ water. In both the fasting and fed conditions, no food was allowed for $4 \mathrm{~h}$ after dosing. Water was permitted as desired, except for $1 \mathrm{~h}$ before and after taking the medicine. The high-calorie and high-fat breakfast (800-1000 calories) contains 150 calories from protein, 250 calories from carbohydrates and 500-600 calories from fat with the following approximate composition, 1 boiled egg, 2 slices of waffles, 1 Starbucks bacon egg sandwich and $250 \mathrm{ml}$ of milk.

Blood samples (3 $\mathrm{ml}$ each) for PK analysis were collected in vacutainers containing $\mathrm{K}_{2}$ EDTA at the following time points, pre-dose and $0.5,1,1.5,1.75$, $2,2.25,2.5,3,3.5,4,6,8,12$ and $24 \mathrm{~h}$ post-dose. The blood samples were placed in an ice bath and immediately centrifuged at $4000 \mathrm{rpm}$ at $4^{\circ}$ for $5 \mathrm{~min}$. The separated plasma was stored at $-20^{\circ}$ temporary and transferred to $-70^{\circ}$ within $12 \mathrm{~h}$.

Plasma cefuroxime axetil concentrations were measured using a separately validated liquid chromatography coupled with a tandem mass spectrometry (LC-MS/ MS) method. The stock and working solutions of analyte and internal standard were prepared in a diluent mixture comprising $50 \%$ acetonitrile in water (with $1 \%$ formic acid). A gradient method, running at a flow rate of $0.8 \mathrm{ml} / \mathrm{min}$ on a Welch, Ultimate $\mathrm{XB} \mathrm{C}_{18}$,

This is an open access article distributed under the terms of the Creative Commons Attribution-NonCommercial-ShareAlike 3.0 License, which allows others to remix, tweak, and build upon the work non-commercially, as long as the author is credited and the new creations are licensed under the identical terms

Accepted 08 July 2019

Revised 12 March 2019

Received 15 January 2019

Indian J Pharm Sci 2019;81(5):966-970 
$2.1 \times 50 \mathrm{~mm}, 3 \mu \mathrm{m}$ column, provided sample stacking and separation for the analyte. Cefuroxime axetil and the internal standard (Cefuroxime-d3) were ionized in the negative ion spray mode and detected through multiple reaction monitoring of mass transition pairs at $423.2 \rightarrow 207.0$ and $426.2 \rightarrow 210.0 \mathrm{~m} / \mathrm{z}$, respectively. Assay linearity was achieved over a concentration range of 10 to $10000 \mathrm{ng} / \mathrm{ml}$ for cefuroxime axetil in human plasma samples. The lower limits of quantitation (LLOQ) was $10 \mathrm{ng} / \mathrm{ml} \mathrm{C}_{\text {max }}, \mathrm{AUC}_{0-\mathrm{t}}, \mathrm{AUC}_{0-\infty}, \mathrm{T}_{\max }, \mathrm{t}_{1 / 2}$, $\mathrm{Vd}, \mathrm{CL}$ were estimated using a non-compartmental model in WinNonlin ${ }^{\circledR}$ professional software (v 6.4).

Statistical analysis was performed using student T-test (IBM®SPSS Statistics V22.0, IBM, NY, USA) with p-values less than 0.05 as the level of significance. All experiments were expressed as the mean $\pm \mathrm{SD}$.

The clinical safety was assessed via medical history, clinical examination (physical and systemic examination), vital signs (blood pressure, heart rate and body temperature), laboratory tests (hematology, biochemistry, urine analysis) and ECGs from screening to exit examination. Pregnancy urine test for female subjects was done. Each subject was questioned periodically throughout the study regarding adverse effects (AEs). Version 4.02 of the National Cancer Institute (NCI) common terminology criteria for AEs was used for toxicity and $\mathrm{AE}$ reporting.
The study was conducted in Chinese male and female population. Twenty-three (17 male and 6 female) healthy Chinese subjects completed this study. Three subjects withdrew (two for unrelated reasons, one was due to an abnormality in the laboratory test). Data for these 3 discontinued subjects were not included. Subjects were aged between 21 and $41 \mathrm{y}$. Body weight ranged from 47.0 to $79.0 \mathrm{~kg}$. BMI ranged from 20.3 to $25.9 \mathrm{~kg} / \mathrm{m}^{2}$. The data of demographic characteristics of study subjects was shown in Table 1.

The effect of food on the plasma concentration profile of cefuroxime axetil was evaluated at an oral dose of $250 \mathrm{mg}$ in male and female healthy subjects. The mean cefuroxime axetil plasma concentration-time profiles after administration with or without a high-fat meal are shown in fig. 1, while the pharmacokinetic parameters are summarized in Table 2. Pharmacokinetic parameters (following student analysis) under fasting and fed conditions given in Table 3 . We could observe that most of the pharmacokinetic parameters (except $\mathrm{C}_{\text {max }}$, $\mathrm{P}=0.419>0.05)$ of cefuroxime axetil were influenced by food intake.

A pharmacokinetic comparison was made to prove the possible existence of differences of metabolic characteristics between males and females. There were no significant differences between male and female subjects in $\mathrm{T}_{\max }, \mathrm{C}_{\max }, \mathrm{AUC}, \mathrm{t}_{1 / 2}, \mathrm{Vd}$ or CL (Table 4).

TABLE 1: DEMOGRAPHIC CHARACTERISTICS OF STUDY SUBJECTS

\begin{tabular}{lccc}
\hline & Male subjects $(\mathrm{n}=17$, mean \pm SD) & Female subjects $(\mathrm{n}=6$, mean \pm SD) & All subjects $(\mathrm{mean} \pm$ SD) \\
\hline Age $(\mathrm{y})$ & $21-40(29 \pm 5)$ & $24-41(30 \pm 6)$ & $21-41(29 \pm 5)$ \\
Height $(\mathrm{m})$ & $1.60-1.78(1.70 \pm 0.05)$ & $1.52-1.63(1.58 \pm 0.05)$ & $1.52-1.78(1.67 \pm 0.07)$ \\
Weight $(\mathrm{kg})$ & $59.5-79.0(67.0 \pm 5.7)$ & $47.0-67.1(54.8 \pm 7.3)$ & $47.0-79.0(63.8 \pm 8.1)$ \\
BMl $\left(\mathrm{kg} . \mathrm{m}^{-2}\right)$ & $20.6-25.9(23.1 \pm 1.6)$ & $20.3-25.3(21.9 \pm 1.8)$ & $20.3-25.9(22.8 \pm 1.7)$ \\
\hline
\end{tabular}

Data are the minimum to maximum, BMI body mass index

TABLE 2: PLASMA PK PARAMETERS OF CEFUROXIME AXETIL UNDER FASTING AND FED CONDITIONS

\begin{tabular}{lccc}
\hline Pharmacokinetic Parameters & Fasting $(\mathrm{n}=23$, mean \pm SD) & Fed $(\mathrm{n}=23$, mean \pm SD) & $90 \% \mathrm{Cl}(\mathrm{range})$ \\
\hline $\mathrm{T}_{\max }(\mathrm{h})$ & $2.23 \pm 1.14$ & $3.01 \pm 1.31$ & $109.53(96.54-124.27)$ \\
$\mathrm{C}_{\max }\left(\mathrm{ng} \cdot \mathrm{ml}^{-1}\right)$ & $3624 \pm 1304$ & $3892 \pm 883$ & $139.55(127.63-152.59)$ \\
$\mathrm{AUC}_{0-\mathrm{t}}\left(\mathrm{ng} \cdot \mathrm{h} \cdot \mathrm{ml}^{-1}\right)$ & $11928 \pm 3138$ & $16297 \pm 2382$ & $139.86(127.95-152.87)$ \\
$\mathrm{AUC}_{0-\infty}$ (ng.h.ml $\left.{ }^{-1}\right)$ & $12009 \pm 3167$ & $16439 \pm 2405$ & \\
$\mathrm{t}_{1 / 2}(\mathrm{~h})$ & $1.48 \pm 0.15$ & $1.35 \pm 0.15$ & \\
$\mathrm{Vd}(\mathrm{ml} / \mathrm{kg})$ & $45711 \pm 16790$ & $27048 \pm 9328$ & $13965 \pm 4766$ \\
$\mathrm{CL}(\mathrm{ml} /(\mathrm{kg} \cdot \mathrm{h}))$ & $21348 \pm 7358$ & & \\
\hline
\end{tabular}

$\mathrm{Cl}$ confidence interval; $\mathrm{T}_{\max }$ time of peak concentration, $\mathrm{C}_{\max }$ maximum plasma concentration, $\mathrm{AUC}_{0 . \mathrm{t}}$ area under the concentration-time curve from time zero to the time of the last quantifiable concentration, $A U C_{0-\infty}$ area under the concentration-time curve from time zero to infinity, $\mathrm{t}_{1 / 2}$ half-life, $\mathrm{Vd}$ apparent volume of distribution, $\mathrm{CL}$ apparent clearance

TABLE 3: P VALUES OF PHARMACOKINETIC PARAMETERS BETWEEN FASTING AND FED CONDITIONS

\begin{tabular}{llllllll}
\hline Pharmacokinetic Parameters & AUC $_{0-\mathrm{t}}$ & $\mathrm{AUC}_{0-\infty}$ & $\mathrm{C}_{\max }$ & $\mathrm{T}_{\max }$ & $\mathrm{t}_{1 / 2}$ & $\mathrm{Vd}$ & $\mathrm{CL}$ \\
\hline $\mathrm{P}$ & $0.000^{*}$ & $0.000^{*}$ & 0.419 & $0.036^{*}$ & $0.006^{*}$ & $0.000^{*}$ & $0.000^{*}$ \\
\hline${ }^{*} \mathrm{p}<0.05$ & & & & & & &
\end{tabular}


A summary of AEs in healthy subjects after oral cefuroxime axetil under fasting and fed conditions was presented in Table 5. Out of 23 enrolled subjects, three subjects experienced AEs. All $\mathrm{AE}_{\mathrm{S}}$ were mild in nature. Two AEs (headache and fever) that were considered unlikely/remotely related to the drug. There was one AE (glutamic oxaloacetic transaminase increased) that was considered to possibly relate to the drug. Overall, cefuroxime axetil was well tolerated under fasting and fed conditions by healthy human subjects.

a
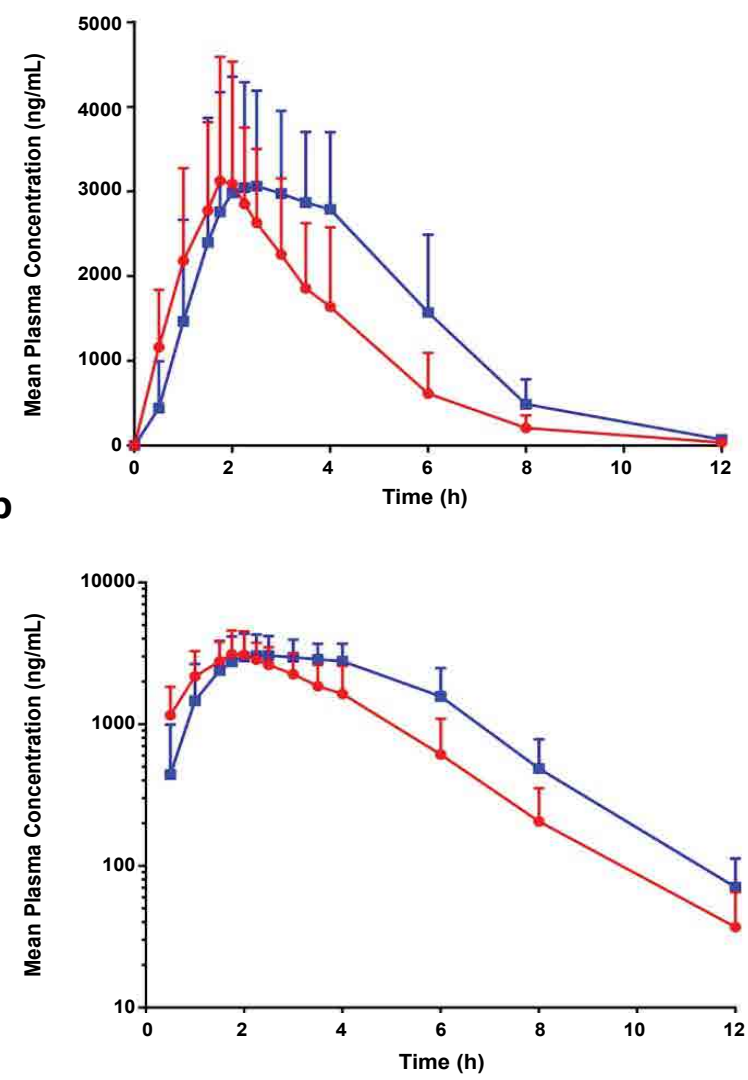

Fig. 1: Plasma concentration time profiles of cefuroxime axetil under fasting and fed conditions

(a) mean plasma concentration of cefuroxime axetil under fasting and fed conditions and (b) logarithmic transformation of mean plasma concentration (Y-axis), error bars represent

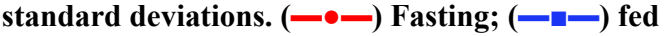

Many studies pointing to the effect of food on the pharmacokinetics of cefuroxime axetil, were studied in the early years, but most of them were focused on western populations and the pharmacokinetic parameters were relatively simple ${ }^{[3-5,8,11]}$. Only one study was conducted on Chinese adults and the apparent clearance was compared ${ }^{[10]}$. In this study, CL and $\mathrm{Vd}$ of cefuroxime axetil alone or with food based on an open-label, two-period design were compared. The safety and gender differences were also evaluated in pharmacokinetic of cefuroxime axetil in Chinese healthy, adult human subjects.

Pharmacokinetic parameters for the regimen with food were found to be slightly different from those reported by Chen et al. ${ }^{[10]}$, who observed $\mathrm{AUC}_{0-\infty}$ value of $23.46 \pm 4.57$ $\mathrm{mg} / \mathrm{l} . \mathrm{h}, \mathrm{T}_{\max }$ and $\mathrm{C}_{\max }$ values of $7.10 \pm 1.41 \mathrm{mg} / \mathrm{l}$ and $2.04 \pm 1.32 \mathrm{~h}, \mathrm{CL}$ values of $21.93 \pm 5.18 \mathrm{l} / \mathrm{h}$ but similar to Kees et al. ${ }^{[11]}$ reported $\mathrm{C}_{\max }, \mathrm{T}_{\max }$ and AUC values of $4.69 \pm 1.58 \mu \mathrm{g} / \mathrm{ml}, 2.13 \pm 0.48 \mathrm{~h}$ and $14.3 \pm$ $3.1 \mu \mathrm{g} / \mathrm{ml}$.h. In the present study, AUC and $\mathrm{T}_{\max }$ were significantly increased after oral administration with food when compared to fasting condition $(\mathrm{p}<0.05)$; $t_{1 / 2}, V d$ and CL were significantly lower under the fed condition.

The exact reasons for these findings cannot fully be delineated by the present study, but the complex nature of the meals (in which one should consider such variables as volume, mixture of solids and liquids, $\mathrm{pH}$, osmolality and gastric $\mathrm{pH}$ on cefuroxime axetil absorption) might impact on gastric $\mathrm{pH}$ and emptying, hepatic extraction, and renal excretion, all of which could alter the pharmacokinetics of cefuroxime axetil $^{[12-14]}$. The development of food-drug interactions may also depend on the size and the composition of a meal as well as the exact timing of drug intake in relation to a meal ${ }^{[15]}$. One study explained that fat, as in the high-fat diet, could stimulate gastric acid secretion and slow gastric emptying by means of effects on receptors in the gastric antrum and duodenum. It

TABLE 4: PHARMACOKINETIC PARAMETERS OF CEFUROXIME AXETIL UNDER FASTING AND FED CONDITIONS IN MALE AND FEMALE

\begin{tabular}{|c|c|c|c|c|c|c|}
\hline \multirow{2}{*}{$\begin{array}{l}\text { Pharmacokinetic } \\
\text { parameters }\end{array}$} & \multicolumn{3}{|c|}{ Fasting } & \multicolumn{3}{|c|}{ Fed } \\
\hline & Male & female & Sig & Male & female & Sig \\
\hline$T_{\max }(\mathrm{h})$ & $2.37 \pm 1.20$ & $1.83 \pm 0.92$ & 0.335 & $2.97 \pm 1.19$ & $3.13 \pm 1.73$ & 0.811 \\
\hline $\mathrm{C}_{\max }\left(\mathrm{ng} \cdot \mathrm{ml}^{-1}\right)$ & $3679 \pm 1458$ & $3470 \pm 804$ & 0.745 & $3953 \pm 722$ & $3720 \pm 1308$ & 0.693 \\
\hline $\mathrm{AUC}_{0-\mathrm{t}}\left(\mathrm{ng} \cdot \mathrm{h} \cdot \mathrm{ml}^{-1}\right)$ & $12201 \pm 3331$ & $11153 \pm 2620$ & 0.495 & $16776 \pm 1875$ & $14941 \pm 3275$ & 0.106 \\
\hline $\mathrm{AUC}_{0-\infty}$ (ng.h. $\left.\mathrm{ml}^{-1}\right)$ & $12295 \pm 3363$ & $11196 \pm 2623$ & 0.478 & $16931 \pm 1928$ & $15046 \pm 3225$ & 0.100 \\
\hline$t_{1 / 2}(h)$ & $1.49 \pm 0.16$ & $1.47 \pm 0.11$ & 0.798 & $1.39 \pm 0.14$ & $1.26 \pm 0.16$ & 0.071 \\
\hline $\mathrm{Vd}(\mathrm{ml} / \mathrm{kg})$ & $44415 \pm 18375$ & $49384 \pm 11751$ & 0.546 & $28433 \pm 8169$ & $23122 \pm 12012$ & 0.239 \\
\hline $\mathrm{CL}(\mathrm{ml} /(\mathrm{kg} \bullet \mathrm{h}))$ & $20668 \pm 8069$ & $23275 \pm 4880$ & 0.468 & $14196 \pm 4003$ & $13308 \pm 6925$ & 0.704 \\
\hline
\end{tabular}

Male $(n=17)$ and female $(n=6)($ mean $\pm S D, n=23)$, significant (at 0.05 level) 
TABLE 5: ADVERSE EVENTS IN HEALTHY SUBJECTS AFTER ORAL CEFUROXIME AXETIL UNDER FASTING AND FED CONDITIONS

\begin{tabular}{lcc}
\hline Adverse events & Fasting no (\%) & Fed no (\%) \\
\hline Headache & $1(4.3)$ & $0(0)$ \\
Fever & $1(4.3)$ & $0(0)$ \\
Glutamic oxaloacetic & $0(0)$ & $1(4.3)$ \\
transaminase increased & $0)$
\end{tabular}

also explained that the presence of food may lead to prolonged residence time at a site in the intestine from which absorption, or hydrolysis of an ester pro-drug by nonspecific esterases in the intestinal wall to active drug (cefuroxime), is optimal ${ }^{[16]}$.

As for the gender effect, the pharmacokinetic parameters of cefuroxime axetil were similar between male and female subjects, our result was in accord with previous studies ${ }^{[6,8]}$. Moreover, oral administration of cefuroxime axetil appeared to be well tolerated. All AEs were of mild intensity and transient. No serious AEs were reported.

Although some reports in the literature showed similar results, but pharmacokinetic studies of 250 mg cefuroxime axetil oral formulation among fasting versus fed healthy Chinese subjects was not reported. The present study would be helpful to obtain kinetics data to study the food effects of cefuroxime axetil in China population.

\section{Acknowledgements:}

The authors would like to thank the staff in the study team and all study subjects. This work was supported by Nanjing Youth Health Talents Project (QRX11032) (Nanjing First Hospital Ethics Committee approval number YW20170904).

\section{Conflicts of interest:}

There are no conflicts of interest.

\section{REFERENCES}

1. Akman C, Duran A, Kalafat UM, Ocak T. Uveitis attack and drug reaction due to cefuroxime axetil. Cutan Ocul Toxicol 2016;35(3):254-56.
2. Dalal N, Buckner IS, Wildfong PLD. Experimental Determination and Theoretical Calculation of the Eutectic Composition of Cefuroxime Axetil Diastereomers. AAPS PharmSciTech 2017;18(7):2570-8.

3. Finn A, Straughn A, Meyer M, Chubb J. Effect of dose and food on the bioavailability of cefuroxime axetil. Biopharm Drug Dispos 1987;8(6):519-26.

4. Sommers DK, van Wyk M, Moncrieff J, Schoeman HS. Influence of food and reduced gastric acidity on the bioavailability of bacampicillin and cefuroxime axetil. $\mathrm{Br} \mathrm{J}$ Clin Pharmacol 1984;18(4):535-9.

5. Ginsburg CM, McCracken GH Jr, Petruska M, Olson K. Pharmacokinetics and Bactericidal Activity of Cefuroxime Axetil. Antimicrob Agents Chemother 1985;28(4):504-7.

6. Harding SM, Williams PE, Ayrton J. Pharmacology of Cefuroxime as the 1-acetoxyethyl ester in subjects. Antimicrob Agents Chemother 1984;25(1):78-82.

7. Fuchs T. Case Study: Cefuroxime Axetil: An Oral Prodrug of Cefuroxime. In: Stella, Valentino J, editors. Prodrugs: Challenges and Rewards. Part 1. New York: Springer; 2007.p.1195-205.

8. Williams PE, Harding SM. The absolute bioavailability of oral cefuroxime axetil in male and female subjects after fasting and after food. J Antimicrob Chemother 1984;13(2):191-6.

9. Vasu S, Adithan C, Shashindran CH, Asad M, Koumaravelou K, Topno I. Effect of two types of Indian breakfast on bioavailability of cefuroxime axetil. Indian $\mathrm{J}$ Med Res 2000;112:104-8.

10. Chen RR, Lee TY, Hsieh WC. Effect of food on pharmacokinetics of cefuroxime axetil in Chinese subjects. J Formos Med Assoc 1992;91(12):1177-81.

11. Kees F, Lukassek U, Naber KG. Comparative Investigations on the Bioavailabil of Cefuroxime Axetil. Arzneimittelforschung 1991;41:843-6.

12. Schmidt LE, Dalhoff K. Food-Drug Interactions. Drugs 2002;62(10):1481-502.

13. Jammula S, Patra ChN, Swain S, Panigrahi KC, Nayak S, Dinda $\mathrm{SC}$, et al. Design and characterization of cefuroxime axetil biphasic floating minitablets. Drug Deliv 2015;22(1):125-35.

14. Asiri YA, Al-Hadiya BM, Kadi AA, Al-Khamis KI, Mowafy HA, El-Sayed YM. Comparative bioavailability study of cefuroxime axetil (equivalent to $500 \mathrm{mg}$ cefuroxime/tablet) tablets (Zednad $\AA$ versus Zinnat $\left.{ }^{\circledR}\right)$ in healthy male subjects. Int J Clin Pharmacol Ther 2011;49(9):571-6.

15. Singh BN. Effects of food on clinical pharmacokinetics. Clin Pharmacokinet 1999;37(3):213-55.

16. Hughes GS, Heald DL, Barker KB, Patel RK, Spillers CR, Watts $\mathrm{KC}$, et al. The effects of gastric $\mathrm{pH}$ and food on the pharmacokinetics of a new oral cephalosporin, cefpodoxime proxetil. Clin Pharmacol Ther 1989;46(6):674-85. 